\title{
Determinants and assessment of regurgitation after mitral valve repair
}

Eric Lim, MB, ChB, MRCS ${ }^{a}$

Ziad A. Ali, MB, ChB ${ }^{a}$

Clifford W. Barlow, DPhil, FRCS (CTh) ${ }^{\mathrm{a}}$

A. Reza Hosseinpour, FRCS ${ }^{a}$

Christopher Wisbey, $\mathrm{BA}^{\mathrm{a}}$

Susan C. Charman, MSc ${ }^{b}$

Francis C. Wells, MS, FRCS

John B. Barlow, HonDSc, MD, FRCP

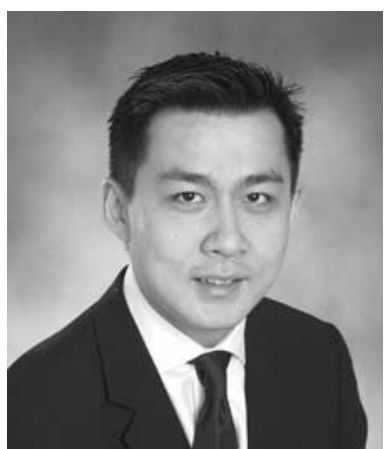

Dr. Lim
Objectives: The ability to detect residual regurgitation is important in the management of patients after mitral valve repair. We performed a study of 264 patients to determine the risk factors and to compare the accuracy of clinical assessment with that of echocardiography.

Methods: Operative details and valve pathologic data were obtained from individual patient case notes. Clinical assessment consisted of history, examination, and electrocardiography. The presence of regurgitation was ranked in 7 grades, from none to severe. Transthoracic echocardiography was performed blinded to and independently of clinical assessment on the same visit and was graded similarly. Univariate analyses of demographic, etiologic, and operative variables were performed. Significant factors were entered into a multivariate logistic regression model. Sensitivities and specificities were calculated for each diagnostic modality, and the $\kappa$ statistic was used to express agreement.

Results: Mean ( \pm SE) freedoms from regurgitation at 1 and 5 years were $91.5 \% \pm$ $1.7 \%$ and $47.5 \% \pm 3.2 \%$. Factors independently associated with postoperative regurgitation were poor ventricular function $(P=.04)$, increased age $(P=.01)$, and chordal procedures $(P=.006)$. When assessing the presence of regurgitation, auscultation conferred a specificity of $78 \%$, a sensitivity of $77 \%$, and a $\kappa$ of 0.43 relative to echocardiography. Electrocardiographic criteria for left ventricular hypertrophy were superior, with a complete specificity of $100 \%$ but a low sensitivity of $15 \%$. Agreement within 7 grades of severity was moderate, with a weighted $\kappa$ value of 0.42 .

Surgery, Papworth Hospital, ${ }^{\text {a }}$ MRC Biostatistics Unit, ${ }^{\mathrm{b}}$ Cambridge, United Kingdom, and the Division of Cardiology, Department of Internal Medicine, University of Witwatersrand and Johannesburg Hospital, Johannesburg, South Africa. ${ }^{\mathrm{c}}$

Received for publication Nov 6, 2001; revisions requested Dec 18, 2001; revisions received March 7, 2002; accepted for publication March 26, 2002.

Address for reprints: Eric $\mathrm{Lim}, \mathrm{MB}, \mathrm{ChB}$, MRCS, Department of Cardiothoracic Surgery, Royal Brompton Hospital, Sydney St, London SW3 6NP, United Kingdom (Email: ericlim2@hotmail.com).

J Thorac Cardiovasc Surg 2002;124:911-7

Copyright (C) 2002 by The American Association for Thoracic Surgery

$0022-5223 / 2002 \$ 35.00+0 \quad \mathbf{1 2 / 1 / 1 2 5 3 4 1}$

doi: $10.1067 / \mathrm{mtc} .2002 .125341$
Conclusions: The hazard function for regurgitation after mitral repair increases steadily after the third year, with ventricular function, age and chordal procedures as independent risks. Clinical assessment and electrocardiography are excellent in identifying regurgitation, but their agreement is less when grading severity.

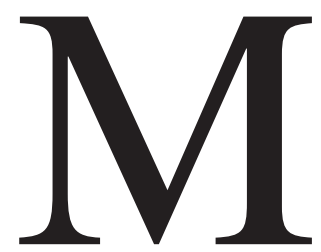

itral valve repair is established as the procedure of choice for the surgical correction of mitral regurgitation. ${ }^{1}$ Unlike valve replacement, surgical correction with repair techniques reconstructs and preserves the innate architecture of the mitral apparatus. Perfect competence is not always achievable, and trivial to mild residual regurgitation is present in $63 \%$ to $64 \%$ of patients after this procedure..$^{2,3}$

Long-term follow up studies now reveal that residual regurgitation after mitral repair is an independent risk for late reoperation. ${ }^{4}$ Therefore, the ability to accurately assess and quantify the degree of residual regurgitation is important both in the 
TABLE 1. Clinical assessment of the severity of regurgitation

\begin{tabular}{|c|c|c|c|}
\hline $\begin{array}{l}\text { Degree of } \\
\text { regurgitation }\end{array}$ & Auscultation & Palpation & ECG \\
\hline 0 (none) & No murmur & Normal & Normal \\
\hline 1 (trivial) & Grade 1-2 pansystolic murmur & Normal & Normal \\
\hline 2 (mild) & $\begin{array}{l}\text { Grade 2-4 late or late accentuating } \\
\text { pansystolic murmur }\end{array}$ & Normal & Normal \\
\hline $\begin{array}{l}3 \text { (mild to } \\
\text { moderate) }\end{array}$ & Grade 3-4 pansystolic murmur & Apex slightly sustained & $\begin{array}{l}\text { Normal or left atrial } \\
\text { enlargement }+\end{array}$ \\
\hline 4 (moderate) & $\begin{array}{l}\text { Grade } 3-4 \text { pansystolic murmur, } 3 \text { rd } \\
\text { heart sound }\end{array}$ & $\begin{array}{l}\text { Apex sustained, left } \\
\text { atrial lift }\end{array}$ & $\begin{array}{l}\text { Left atrial } \\
\quad \text { enlargement }+\end{array}$ \\
\hline $\begin{array}{l}5 \text { (moderate } \\
\text { to severe) }\end{array}$ & $\begin{array}{l}\text { Grade } 2-4 \text { pansystolic murmur, } 3 \text { rd } \\
\text { heart sound, } 2 \text { nd heart sound widely } \\
\text { split, pulmonary component of } 2 \text { nd } \\
\text { heart sound accentuated }\end{array}$ & $\begin{array}{l}\text { Apex sustained and } \\
\text { displaced, left atrial } \\
\text { lift, small volume and } \\
\text { rapid rising pulse }\end{array}$ & $\begin{array}{l}\text { Left atrial } \\
\text { enlargement }++ \text {, } \\
\text { LVH }+\end{array}$ \\
\hline 6 (severe) & $\begin{array}{l}\text { Grade 2-4 pansystolic murmur, 3rd } \\
\text { heart sound, } 2 \text { nd heart sound widely } \\
\text { split, pulmonary component of } 2 \text { nd } \\
\text { heart sound accentuated, aortic } \\
\text { component of } 2 \text { nd heart sound } \\
\text { diminished }\end{array}$ & $\begin{array}{l}\text { Apex sustained and } \\
\text { displaced, left atrial } \\
\text { lift, small volume and } \\
\text { rapid rising pulse }\end{array}$ & $\begin{array}{l}\text { Left atrial } \\
\text { enlargement }++ \text {, } \\
\text { LVH }++\end{array}$ \\
\hline
\end{tabular}

Each plus sign is a subjective indicator of severity.

postoperative management and in the decision as to the intensity of subsequent reviews. Considerable controversy exists regarding the optimal method of follow-up, and no consensus has been achieved in favor of either clinical examination alone or periodic echocardiography. ${ }^{5}$ The aim of this study was to determine the risk factors and compare the accuracy of clinical examination with that of transthoracic echocardiography in assessing the presence and severity of residual postoperative mitral regurgitation.

\section{Methods}

This study was based on 264 patients who attended a series of clinics from February to September 1999 that were conducted specifically for this review. Patients were invited to participate if they had mitral regurgitation (confirmed by clinical, echocardiographic, and angiographic assessment) and underwent surgical repair between 1987 and 1998.

For each patient, clinical and transthoracic echocardiographic assessment was performed blind and independently during the same visit. The results were compared to determine the accuracy of clinical examination in detecting mitral regurgitation and the ability to discern between grades of regurgitation.

The cause of valvular regurgitation was determined by histopathologic examination of operatively obtained valve specimens. Operative details and evaluation of valve disease were obtained by scrutiny of individual patient operation notes.

\section{Clinical Assessment}

Assessment consisted of history, clinical examination and electrocardiography (ECG). On admission, the ECG was recorded for each patient before interview and clinical examination undertaken by a cardiologist with a particular interest in and experience with mitral valve disease (J.B.B.). Mitral regurgitation was documented and graded in 7 categories (none, trivial, mild, mild to moderate, moderate, moderate to severe, and severe) according to previously published criteria. ${ }^{6}$ Clinical criteria used to grade the severity of regurgitation are presented in Table 1 . The presence of left ventricular hypertrophy $(\mathrm{LVH})$ was determined according to the voltage criteria of Sokolow and Lyon $\left(\mathrm{SV}_{1}+\mathrm{RV}_{5 / 6}>38 \mathrm{~mm}\right)$, and strain pattern was defined as downwardly sloping convex ST segments with inverted asymmetric T-wave inversion opposite to the QRS axis in $\mathrm{V}_{5 / 6}{ }^{7}$

\section{Echocardiographic Assessment}

Transthoracic echocardiography was performed by an experienced echocardiographer (C.R.W.) on a Hewlett-Packard Sonos 2500 echocardiography machine (Hewlett-Packard Company, Palo Alto, Calif) with spectral and color flow Doppler techniques to evaluate postoperative mitral regurgitation. The degree of regurgitation according to echocardiography was categorized into 7 grades as none, trivial, mild, mild to moderate, moderate, moderate to severe, and severe.

Each of the Doppler techniques was used to assess the overall grade of mitral regurgitation. Color flow Doppler was used to assess the width at the origin of the regurgitant jet, with broader jets indicating progressive degrees of regurgitation. The direction of the jet was determined from the color flow signal. Continuouswave Doppler was used to grade the amount of regurgitation, with care being taken to align the continuous-wave beam with the strongest received signal. The brightness of the mitral regurgitation envelope was visually compared with that of the mitral valve forward flow envelope, and envelopes equal to or approaching the brightness of the mitral valve forward flow were taken to indicate severe mitral regurgitation. Incomplete envelopes and complete but pale envelopes were interpreted as mild mitral regurgitation. Pulsed-wave Doppler was used to track the regurgitant jet. The 
TABLE 2. Echocardiographic assessment of the severity of regurgitation

\begin{tabular}{|c|c|c|c|}
\hline $\begin{array}{l}\text { Degree of } \\
\text { regurgitation }\end{array}$ & Color flow Doppler & Continuous wave Doppler & Pulsed wave Doppler \\
\hline 0 (none) & No jet & No envelope & No jet \\
\hline 1 (trivial) & $\begin{array}{l}\text { Very narrow jet, } \\
\text { length }<5 \mathrm{~mm}\end{array}$ & $\begin{array}{l}\text { Minimal envelope } \\
\text { definition, often just } \\
\text { leading edge }\end{array}$ & $\begin{array}{l}\text { Weak jet, }<5 \mathrm{~mm} \text { in } \\
\text { duration }\end{array}$ \\
\hline 2 (mild) & $\begin{array}{l}\text { Narrow, short-lived } \\
\text { jet, width }<2 \mathrm{~mm}\end{array}$ & Incomplete envelope & $\begin{array}{l}\text { Jet weak, }<0.25 \text { of left } \\
\text { atrium }\end{array}$ \\
\hline $\begin{array}{l}3 \text { (mild to } \\
\text { moderate) }\end{array}$ & Jet width 2-5 mm & Complete, pale envelope & $\begin{array}{l}\text { Jet traced between } 0.25 \\
\text { and } 0.5 \text { of left atrium }\end{array}$ \\
\hline 4 (moderate) & Jet width $>5 \mathrm{~mm}$ & $\begin{array}{l}\text { Complete envelope, } \\
\text { moderately bright }\end{array}$ & $\begin{array}{l}\text { Moderate jet, }>0.5 \text { of left } \\
\text { atrium }\end{array}$ \\
\hline $\begin{array}{l}5 \text { (moderate } \\
\text { to severe) }\end{array}$ & Jet width $>5 \mathrm{~mm}$ & $\begin{array}{l}\text { Complete envelope, not } \\
\text { as bright as mitral } \\
\text { valve forward flow }\end{array}$ & $\begin{array}{l}\text { Moderate jet, }>0.5 \text { of left } \\
\text { atrium }\end{array}$ \\
\hline 6 (severe) & Jet width $>5 \mathrm{~mm}$ & $\begin{array}{l}\text { Complete envelope, } \\
\text { bright as mitral valve } \\
\text { forward flow }\end{array}$ & $\begin{array}{l}\text { Strong jet, traced length of } \\
\text { left atrium, pulmonary } \\
\text { venous flow reversal }\end{array}$ \\
\hline
\end{tabular}

echocardiographic criteria used to grade the severity of regurgitation are presented in Table 2.

\section{Statistical Methods}

Continuous variables are presented as mean \pm SD or median with interquartile range. Non-risk-adjusted estimates of freedom from regurgitation were obtained by the method of Kaplan-Meier. Univariate analysis of demographic, etiologic, and operative exploratory variables (Tables 3 and 4) was performed to approximate the risk of residual regurgitation on follow-up. Significant factors were entered into a multivariate logistic regression model, where significance was determined by the likelihood ratio test.

The $\kappa$ statistic was used to determine the degree of agreement beyond chance in comparing the accuracy of clinical examination compared with echocardiography. A weighted $\kappa$ was also computed to express the degree of agreement between the presence and severity of regurgitation in 7 grades ranging from 0 to 6 . Interpretation of the $\kappa$ statistic was based on the guidelines of Landis and Koch. ${ }^{8}$ Sensitivities and specificities were calculated with $95 \%$ confidence intervals (CIs) for each of the diagnostic modalities reported.

\section{Results}

From the December 1987 through September 1998, a total of 360 patients underwent mitral valve repair at our institution. In 1999, a total of 296 survivors were contacted, and 264 accepted the invitation for enrollment at a median interval of 47.5 months (interquartile range 20.0-82.3 months) from surgery. Patient characteristics, valve pathologic entities, and operative procedures are presented in Tables 3 and 4.

\section{Determinants of Postoperative Echocardiographic Regurgitation}

Freedom from residual regurgitation $( \pm \mathrm{SE})$ at 1 and 5 years were $91.5 \% \pm 1.7 \%$ and $47.5 \% \pm 3.2 \%$, respectively. Factors significantly associated with postoperative regurgi- tation were preoperative left ventricular function $(P=$ .006), preoperative atrial fibrillation $(P=.05)$, age $(P=$ $.01)$, and chordal repair and replacement procedures $(P=$ .02). Preoperative LVH approached traditional levels of significance $(P=.07)$. In the final model, only preoperative left ventricular function $(P=.04)$, age $(P=.01)$, and chordal procedures $(P=.006)$ remained significant. The odds ratio comparing echocardiographic detection of regurgitation with moderate to good left ventricular function was 2.3 (95\% CI 1.1-4.8); that for poor to good function was 2.9 (95\% CI 0.8-10.0). The odds ratio per additional year of age was 1.0 (95\% CI 1.0-1.1), and the odds ratio comparing those with chordal procedures with those without was 8.7 (95\% CI 1.1-68.0). The wide confidence interval reflects the high proportion of patients with chordal procedures with residual regurgitation $(n=27 / 28)$.

\section{Comparison of Modalities to Detect Mitral Regurgitation}

Most patients were in New York Heart Association functional class I or II $(96.1 \%$ of patients without regurgitation compared with $94.4 \%$ of patients with regurgitation; $P=$ .62). Of the 113 patients in New York Heart Association functional class I on follow-up, 72.6\% $(n=82 / 113)$ had evidence of regurgitation on echocardiography. This included $6.2 \%(n=7 / 113)$ of patients with regurgitation of moderate severity.

A total of $67.0 \%$ of patients had a murmur detectable by clinical examination. This was reasonably accurate, with a sensitivity of $78 \%$ (95\% CI 72\%-83\%) and a specificity of $77 \%$ (95\% CI 64\%-89\%). The calculated $\kappa$ statistic for this observation was 0.42 (95\% CI 0.31-0.54), which indicates moderate agreement with echocardiography. The positive predictive value was $93 \%$ (95\% CI 89\%-96\%), the negative 
TABLE 3. Patient characteristics

\begin{tabular}{|c|c|c|c|}
\hline \multirow[b]{2}{*}{ Variable } & \multirow[b]{2}{*}{ Value } & \multicolumn{2}{|c|}{ Risk of regurgitation } \\
\hline & & Odds ratio & $95 \% \mathrm{Cl}$ \\
\hline Sample size (No.) & 264 & & \\
\hline Age $(y$, mean $\pm S D)$ & $63 \pm 11$ & 1.0 & $1.0-1.07^{*}$ \\
\hline Male patients (No.) & $171(64.8 \%)$ & 0.57 & $0.29-1.1$ \\
\hline \multicolumn{4}{|l|}{ Left ventricular function (No.) } \\
\hline Normal function & $139(52.7 \%)$ & 1 & \\
\hline Moderate impairment & $92(34.8 \%)$ & 2.7 & $1.3-5.5$ \\
\hline Severe impairment & $33(12.5 \%)$ & 3.6 & $1.0-12$ \\
\hline \multicolumn{4}{|c|}{$\begin{array}{l}\text { Preoperative New York Heart Association } \\
\text { functional class (No.) }\end{array}$} \\
\hline I or II & $81(30.7 \%)$ & 1 & \\
\hline III or IV & $183(69.3 \%)$ & 1.6 & $0.85-3.0$ \\
\hline \multicolumn{4}{|l|}{ Preoperative rhythm (No.) } \\
\hline Sinus & $170(64.4 \%)$ & 1 & \\
\hline Atrial fibrillation & $91(34.5 \%)$ & 2.0 & $1.0-4.1$ \\
\hline Other & $3(1.1 \%)$ & & \\
\hline Preoperative LVH (No.) & $103(39.0 \%)$ & 1.9 & $0.96-3.7$ \\
\hline \multicolumn{4}{|c|}{ Etiology of mitral regurgitation (No.) } \\
\hline Degenerative & $210(79.5 \%)$ & 1 & \\
\hline Rheumatic & $20(7.6 \%)$ & 1.6 & $0.43-5.5$ \\
\hline Endocarditis & $20(7.6 \%)$ & 2.5 & $0.55-11.0$ \\
\hline Ischemic & $13(14.9 \%)$ & 3.3 & $0.41-26.0$ \\
\hline Traumatic & $1(0.4 \%)$ & $-\dagger$ & \\
\hline \multicolumn{4}{|c|}{$\begin{array}{l}\text { Follow-up New York Heart Association } \\
\text { functional class } \ddagger \text { (No.) }\end{array}$} \\
\hline I or II & $250(94.7)$ & - & \\
\hline III or IV & $14(5.3)$ & - & \\
\hline \multicolumn{4}{|l|}{ Follow-up rhythm $\ddagger$ (No.) } \\
\hline Sinus & $167(63.3)$ & - & \\
\hline Atrial fibrillation & $90(34.1)$ & - & \\
\hline Other & $7(2.6)$ & - & \\
\hline Postoperative LVH‡ (No.) & $30(11.4)$ & - & \\
\hline
\end{tabular}

*Risk per additional year.

†The only patient in this subgroup had residual regurgitation.

$\ddagger 0$ dds ratios were not calculated for postoperative variables.

predictive value was $45 \%$ (95\% CI 35\%-55\%), the positive likelihood ratio was 3.3 (95\% CI 2.0-5.4), and the negative likelihood ratio was 0.30 (95\% CI 0.22-0.40).

Electrocardiographic criteria for $\mathrm{LVH}$ were far superior in this respect, providing complete specificity at $100 \%(95 \%$ CI $92 \%-100 \%$ ) but low sensitivity of $15 \%$ (95\% CI $10 \%$ $20 \%)$ when correlated with echocardiography. The positive predictive value was 100\% (95\% CI 89\%-100\%), and the negative predictive value was $22 \%$ (95\% CI $17 \%-28 \%$ ). Strain pattern on electrocardiography provided another useful means of identifying mitral regurgitation, with a specificity of $87 \%$ (95\% CI 74\%-95\%) but a low sensitivity of $29 \%$ (95\% CI $23 \%-35 \%)$.

\section{Comparison of Modalities to assess the Severity of Mitral Regurgitation}

Differentiation among the 7 grades of regurgitation through clinical examination did not correlate well with echocardiographic results. The calculated $\kappa$ for this observation was
0.24 (95\% CI 0.17-0.32). When weighted the agreement was moderate, with a corrected $\kappa$ value of $0.42(95 \% \mathrm{CI}$ $0.34-0.49)$. Of greater clinical relevance, however, is the ability to accurately differentiate between trivial to mild and moderate to severe regurgitation. According to this classification, clinical assessment relative to echocardiography has improved specificity of $88 \%$ (95\% CI $84 \%-93 \%)$ but a poorer sensitivity of $54 \%$ (95\% CI 34\%-69\%) than the presence or absence of regurgitation. The degree of accuracy expressed as $\kappa$ for this was 0.36 (95\% CI $0.19-0.50)$

With the more broadly defined groups for severity of regurgitation, electrocardiographic criteria for $\mathrm{LVH}$ had a specificity of $91 \%$ (95\% CI $87 \%-95 \%)$ and a sensitivity of $38 \%$ (95\% CI 20\%-56\%) in this respect. ECG criteria for strain pattern showed specificity of $78 \%$ (95\% CI 72\%$83 \%$ ) but a sensitivity of $52 \%$ (95\% CI $34 \%-70 \%)$.

A summary of the comparison between clinical assessment and echocardiography was abbreviated to 4 grades, 
TABLE 4. Operative findings, procedures, and associated risks of residual regurgitation

\begin{tabular}{|c|c|c|c|c|}
\hline & \multicolumn{2}{|c|}{ Frequency } & \multicolumn{2}{|c|}{ Risk of regurgitation } \\
\hline & No. & $\%$ & Odds ratio & $95 \% \mathrm{CI}$ \\
\hline \multicolumn{5}{|l|}{ Valve pathology } \\
\hline Annular dilatation & 156 & 59.1 & 1.08 & $0.58-2.0$ \\
\hline Posterior leaflet prolapse & 216 & 81.8 & 0.68 & $0.29-1.6$ \\
\hline Posterior chordal elongation & 189 & 71.6 & 0.65 & $0.31-1.4$ \\
\hline Posterior chordal rupture & 144 & 54.5 & 0.81 & $0.44-1.5$ \\
\hline Anterior leaflet prolapse & 34 & 12.9 & 1.1 & $0.45-2.9$ \\
\hline Anterior chordal elongation & 24 & 9.1 & 1.2 & $0.40-3.8$ \\
\hline Anterior chordal rupture & 7 & 2.7 & 1.5 & $0.17-12.0$ \\
\hline Papillary muscle rupture & 4 & 1.5 & $N A^{*}$ & \\
\hline \multicolumn{5}{|l|}{ Operative procedures } \\
\hline Quadrangular resection & 213 & 80.7 & 0.63 & $0.26-1.5$ \\
\hline Simple annuloplasty & 210 & 79.5 & 0.69 & $0.30-1.6$ \\
\hline Sliding leaflet advance & 91 & 34.5 & 0.78 & $0.42-1.5$ \\
\hline Commissuroplasty & 34 & 12.9 & 0.52 & $0.23-1.2$ \\
\hline $\begin{array}{l}\text { Chordal repair or } \\
\text { replacement }\end{array}$ & 28 & 10.6 & 7.3 & $0.97-55.0$ \\
\hline Anterior leaflet repair & 35 & 13.3 & 1.2 & $0.47-3.0$ \\
\hline Ring annuloplasty & 215 & 81.4 & & \\
\hline None & 49 & 18.6 & 1 & \\
\hline CE Standard $†$ & $189 / 215$ & 87.9 & 0.84 & $0.38-1.87$ \\
\hline Other flexible rings $\ddagger$ & $26 / 215$ & 12.1 & 2.7 & $0.54-13.6$ \\
\hline \multicolumn{5}{|l|}{ Concomitant surgery } \\
\hline $\begin{array}{l}\text { Coronary artery bypass } \\
\text { grafting }\end{array}$ & 45 & 17.0 & 1.1 & $0.49-2.6$ \\
\hline Aortic valve replacement & 9 & 3.4 & $N A^{*}$ & \\
\hline Tricuspid valve repair & 6 & 2.3 & 0.47 & $0.08-2.6$ \\
\hline
\end{tabular}

*All patients in these subgroups had residual regurgitation.

—NA, not applicable.

†Carpentier-Edwards Standard (Baxter Healthcare Corporation CardioVascular Group, Irvine, Calif).

$\ddagger$ Twenty Sculptor rings (Medtronic, Inc, Minneapolis, Minn), 5 Carpentier-Edwards Physio (Baxter Healthcare Corporation CardioVascular Group), 1 Duran ring (Medtronic).

TABLE 5. Comparison of modalities to detect mitral regurgitation

\begin{tabular}{|c|c|c|c|c|c|c|c|c|c|c|}
\hline \multirow[b]{3}{*}{ Clinical } & \multicolumn{10}{|c|}{ Echocardiography } \\
\hline & \multicolumn{2}{|c|}{ None } & \multicolumn{2}{|c|}{ Mild } & \multicolumn{2}{|c|}{ Moderate } & \multicolumn{2}{|c|}{ Severe } & \multicolumn{2}{|c|}{ Total } \\
\hline & No. & $\%$ & No. & $\%$ & No. & $\%$ & No. & $\%$ & No. & $\%$ \\
\hline None & 39 & 14.8 & 45 & 17.0 & 2 & 0.8 & 1 & 0.4 & 87 & 33.0 \\
\hline Mild & 12 & 4.5 & 133 & 50.4 & 21 & 8.0 & 0 & 0 & 166 & 62.9 \\
\hline Moderate & 0 & 0 & 4 & 1.5 & 5 & 1.9 & 0 & 0 & 9 & 3.4 \\
\hline Severe & 0 & 0 & 0 & 0 & 1 & 0.4 & 1 & 0.4 & 2 & 0.8 \\
\hline Total & 51 & 19.3 & 182 & 68.9 & 29 & 11.0 & 2 & 0.8 & 264 & 100 \\
\hline
\end{tabular}

ranging from none, mild, moderate, to severe regurgitation. This is presented in Table 5.

\section{Discussion}

Residual regurgitation after mitral repair is more common than expected. Immediate postoperative transesophageal echocardiography reveals trivial leaks in $98.5 \%$ of patients. ${ }^{4}$ The detected proportion of residual regurgitation was $69 \%$ in our series, consistent with other centers on midterm transthoracic echocardiographic follow-up. ${ }^{2,3}$ Most, however, have clinically insignificant trivial regurgitation $(59 \%$, $\mathrm{n}=107 / 182$ ). Although this finding does not undermine the outstanding results of mitral repair in general, residual regurgitation has been reported as an independent risk for reoperation. ${ }^{4}$ The hazard phase for reoperation tends to occur in two time frames, with the initial peak during the first year followed by a slow and gradual increase in risk with time. ${ }^{9}$ Most failures during the initial peak are presum- 


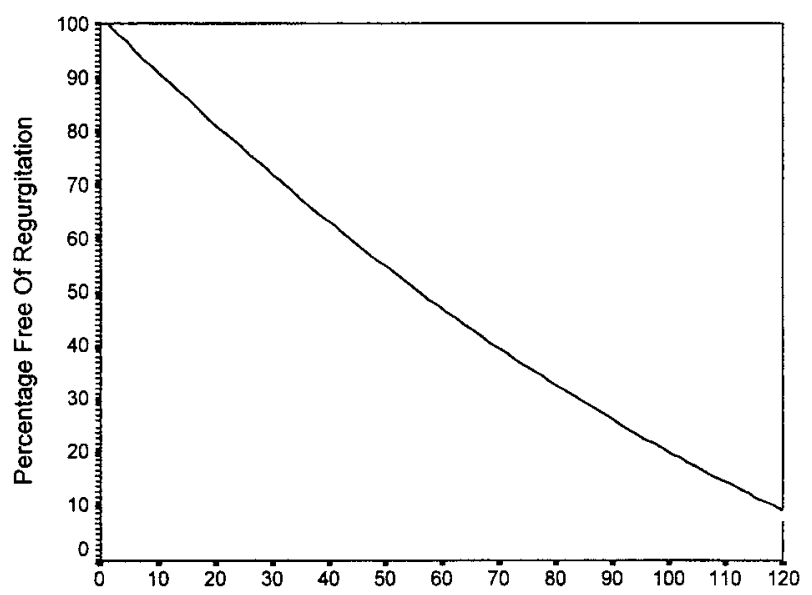

A

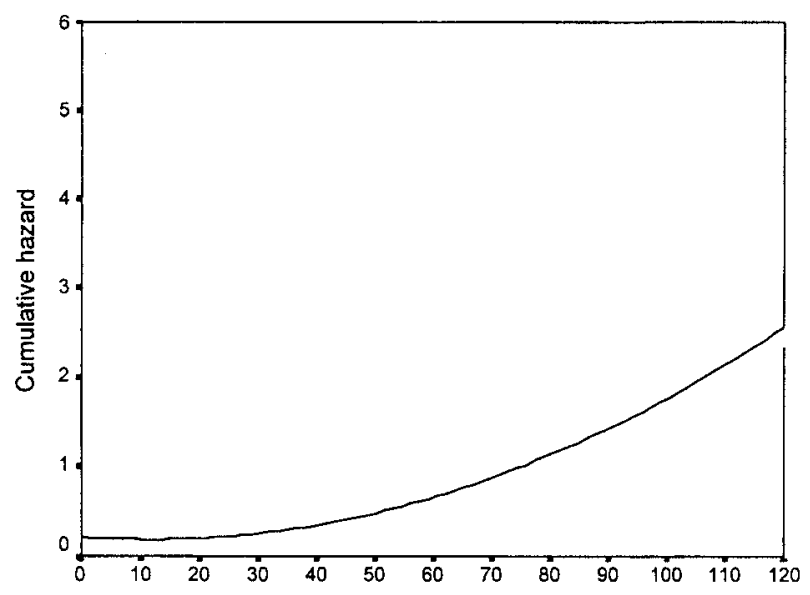

B

Interval (months) after repair

Figure 1. A, Freedom from regurgitation. B, Hazard function for regurgitation.

ably detected and addressed early, so the need for highly predictive testing should decrease with time.

The hazard function for residual regurgitation on the other hand, occurs as a gradual risk that increases steadily after the third year (Figure 1,B). The independent risk factors were impaired preoperative left ventricular function, increased age, and chordal repair or replacement. Among the patients undergoing chordal procedures, there was no difference between the proportions of patients with anterior $(57.1 \%, \mathrm{n}=16 / 28)$ and posterior $(50.0 \%, 14 / 28, P=.25)$ chordal disease.

In the assessment of mitral regurgitation, the popularity of echocardiography has resulted in less emphasis being placed on the clinical assessment. ${ }^{10}$ Although Doppler echocardiography has been considered to be more accurate than auscultation, clinical assessment has the advantage of being inexpensive and repeatable. ${ }^{11}$ The central issue, however, is whether clinical examination is as reliable as echocardiography.

Our results indicate that the agreement on the presence of mitral regurgitation between clinical examination and echocardiography alone is moderate. This may be a reflection of differences in the accuracy of clinical assessment and echocardiography in the detection of mitral regurgitation. Although echocardiography has been reported to be highly accurate $^{11}$ when judged by cardiac catheterization, regurgitant jets may be localized. It is known that inability to position the sample volume in the jet on echocardiography can result in failure to detect regurgitation. ${ }^{12}$ Under these circumstances, an experienced clinical examiner would argue that regurgitation is present when a murmur is detected, even though no regurgitant jet may be seen on echocardiography.

We have discovered that ECG is able to effectively augment the diagnostic process with $100 \%$ specificity to rule in the diagnosis of residual mitral regurgitation in the presence of LVH. All patients in our series with postoperative $\mathrm{LVH}$ also had evidence of residual regurgitation $(11.4 \%, \mathrm{n}=30 / 264)$.

\section{Clinical Implications}

The risk of residual regurgitation after mitral repair escalates after the third year. Where possible, leaflet prolapse should be corrected with procedures other than chordal repair or replacement. Symptoms alone cannot be relied on to guide further management, because regurgitation was present on echocardiography in most symptom-free patients on follow-up. Older patients with more severe left ventricular impairment are at increased risk. Although clinical assessment alone had moderate agreement with echocardiography, when augmented with ECG evidence of LVH it had complete specificity for residual regurgitation. Therefore, clinical assessment and ECG are all that is necessary to detect the presence of regurgitation after mitral repair. Clinical assessment was limited in the ability to discriminate the grades of severity, however, so a combined clinical approach with periodic echocardiography should be used when clinical regurgitation is detected.

\section{Study Limitations}

A cardiologist with extensive experience and interest in mitral valve disease performed the clinical assessment for our study, and not all clinicians may achieve a similar standard. The quality of echocardiography may also vary with operator experience. However, the level of agreement $(\kappa 0.30-0.48)$ is consistent with that found for other cardiologists in the detection of systolic murmurs in general. ${ }^{13}$ Reproducibility of the techniques used in this study may not be exact, because an inherent degree of subjectivity will exist when discriminating the grades of severity of mitral regurgitation for both clinical examination and echocardiography. 
Freedom from regurgitation in Figure 1, A, commences on the assumption that all patients were initially free of regurgitation after the operation. This is clearly not the case in practice, and readers are cautioned to interpret the freedom from regurgitation as a function of time to detection rather than the absence of regurgitation per se.

The inclusion of 15 patients $(5.7 \%, \mathrm{n}=15 / 264)$ with concomitant valve procedures may have prejudiced the clinical examination. However, the decision to include these patients in our study was undertaken to critically evaluate clinical assessment in circumstances reflective of the heterogeneous population encountered in practice.

\section{Conclusions}

Continual surveillance for residual regurgitation is recommended after mitral repair, because the hazard function increases steadily after the third year. Increased age, poor ventricular function, and chordal repair or replacement procedures are independent risk factors for residual regurgitation. Clinical assessment (augmented with ECG evidence of $\mathrm{LVH}$ ) is excellent in detecting the presence of mitral regurgitation. The two modalities, however, have a less powerful correlation in grading the severity of regurgitation.

\section{References}

1. Deloche A, Jebara VA, Relland JY, Chauvaud S, Fabiani JN, Perier P, et al. Valve repair with Carpentier techniques: the second decade. J Thorac Cardiovasc Surg. 1990;99:990-1001.
2. Xu M, McHaffie DJ, Hilless AD. Mitral valve repair: a clinical and echocardiographic study. Br Heart J. 1994;71:51-6.

3. David TE, Armstrong S, Sun Z, Daniel L. Late results of mitral valve repair for mitral regurgitation due to degenerative disease. Ann Thorac Surg. 1993;56:7-12.

4. Mohty D, Orszulak TA, Schaff HV, Avierinos JF, Tajik JA, EnriquezSarano M. Very long-term survival and durability of mitral valve repair for mitral valve prolapse. Circulation. 2001;104(12 Suppl 1):I1-7.

5. Bonow RO, Carabello B, de Leon AC Jr, Edmunds LH Jr, Fedderly BJ, Freed MD, et al. ACC/AHA guidelines for the management of patients with valvular heart disease: a report of the American College of Cardiology/American Heart Association Task Force on Practice Guidelines (Committee on Management of Patients With Valvular Heart Disease). J Am Coll Cardiol. 1998;32:1486-588.

6. Barlow JB, Pocock WA. Mitral regurgitation. In: Barlow, JB, editor. Perspectives on the mitral valve. Philadelphia: Davis; 1987. p. 113-50.

7. Sololow M, Lyon TP. The ventricular complex in left ventricular hypertrophy as obtained by unipolar precordial and limb leads. Am Heart J. 1949;37:161-86.

8. Landis JR, Koch GG. The measurement of observer agreement for categorical data. Biometrics. 1977;33:159-74.

9. Gillinov A, Cosgrove D, Blackstone E, Diaz R, Arnold J, Lytle B, et al. Durability of mitral valve repair for degenerative disease. J Thorac Cardiovasc Surg. 1998;116:734-43.

10. Tofler OB, Tofler GH. Use of auscultation to follow patients with mitral systolic clicks and murmurs. Am J Cardiol. 1990;66:1355-8.

11. Jaffe WM, Roche AH, Coverdale HA, McAlister HF, Ormiston JA, Greene ER. Clinical evaluation versus Doppler echocardiography in the quantitative assessment of valvular heart disease. Circulation. 1988;78:267-75.

12. Come PC, Riley MF, Carl LV, Nakao S. Pulsed Doppler echocardiographic evaluation of valvular regurgitation in patients with mitral valve prolapse: comparison with normal subjects. J Am Coll Cardiol. 1986;8:1355-64.

13. Etchells E, Bell C, Robb K. Does this patient have an abnormal systolic murmur? JAMA. 1997;277:564-71.

\begin{abstract}
Online-www.aats.org
Now you can get The Journal of Thoracic and Cardiovascular Surgery online. The Journal online brings you faster delivery time, easy searching of current and back issues, links to PubMed, AATS, WTSA, and other important sites, and more. Visit the Journal online today.
\end{abstract}

\title{
Receive tables of contents by e-mail
}

To receive the tables of contents by e-mail, sign up through our Web site at http://www.mosby.com/jtcvs

Choose E-mail Notification

Simply type your e-mail address in the box and click the Subscribe button.

Alternatively, you may send an e-mail message to majordomo@mosby.com.

Leave the subject line blank and type the following as the body of your message: subscribe jtcvs_toc

You will receive an e-mail to confirm that you have been added to the mailing list.

Note that TOC e-mails will be sent out when a new issue is posted to the Web site. 